https://doi.org/10.15407/ujpe65.4.291

I. DOROSHENKO, ${ }^{1}$ YE. VASKIVSKYI,${ }^{1,2}$ YE. CHERNOLEVSKA, ${ }^{1,2}$ L. MEYLIEV,${ }^{3}$ B. $\mathrm{KUYLIEV}^{3}$

1 Taras Shevchenko National University of Kyiv

(Kyiv, Ukraine; e-mail: dori11@ukr.net)

2 Jozef Stefan Institute

(Ljubljana, Slovenia)

${ }^{3}$ Karshi State University

(Karshi, Uzbekistan)

\title{
MOLECULAR ISOMERIZATION IN n-PROPANOL DIMERS ${ }^{1}$
}

\begin{abstract}
The molecular isomerization has been studied in n-propanol dimers by quantum-chemical calculations with the DFT method. 25 combinations of molecular pairs are calculated with and without consideration of the dielectric constant of n-propanol. Such approach allowed us to determine the most stable configurations of alcohol dimers. It has been shown that dimers of $n$-propanol are mostly (77.1\%) formed by only 5 of 25 possible configurations at room temperature and by 2 combinations (87.3\%) at the melting point. The size distribution of dimers and the spectral dispersion in the region of free and bonded $\mathrm{O}-\mathrm{H}$ stretching vibrations are calculated.

Keywords: molecular isomerization, dimer, n-propanol, hydrogen bonding, quantum chemistry.
\end{abstract}

\section{Introduction}

Alcohols belong to the class of partially ordered liquids. Due to the presence of a hydroxyl group in their molecules, alcohols can form various cluster structures in condensed phases [1-3] and inert matrix isolation [3-6], in helium nanodroplets [7, 8], in solutions [9], and even in the gas phase [10]. Clusterization processes are intensively studied with different experimental and theoretical techniques [3-14]. In addition to the formation of molecular structures with various sizes, the important role in investigations of a cluster structure of alcohols is played by the molecular isomerization [15-24]. Each molecule of monohydric alcohol with more than one atom of carbon can be found in different conformations. These different conformations are formed due to the rotation of atoms around chemical bonds. Molecules of monohydric alcohols are characterized by three kinds of the isomerism of dihedral angles - trans $\left(\approx 180^{\circ}\right)$, gauche $\left(\approx 60^{\circ}\right)$, and gauche' $\left(\approx-60^{\circ}\right)$ conformers can exist. The studied alcohol - n-propanol with the structural formula $\mathrm{CH}_{2}-\mathrm{CH}_{3}-\mathrm{CH}_{3}-\mathrm{OH}-$ has two struc-

(C) I. DOROSHENKO, YE. VASKIVSKYI, YE. CHERNOLEVSKA, L. MEYLIEV, B. KUYLIEV, 2020

ISSN 2071-0194. Ukr. J. Phys. 2020. Vol. 65, No. 4 tural dihedrals and 9 stable configurations [16, 17], which include one plane structure and 4 pairs of enantiomers (or mirror-image pairs). Since enantiomers have similar energy and optical properties, the difference between them is usually neglected.

Propanol is widely studied, as it is one of the most useable alcohol for various applications. Its conformational properties were studied in supersonic jets [17, 21], cryogenic matrices [6, 17], gas and liquid phases [16], and $\mathrm{CCl}_{4}$ solutions at low concentrations [25]. This research is aimed to determine, if molecular isomerization could lead to a non-uniform distribution of n-propanol dimers consisting of different molecular isomers. The consideration of possible dimer structures of n-propanol at various temperatures can be used in further researches of the molecular isomerization in bigger propanol clusters and in a bulk alcohol.

\section{Calculation Details}

All the calculations in this work were carried out using the Gaussian software [26]. For the visualization

1 The paper was presented at XXIVth Galyna Puchkovska International School-Seminar "Spectroscopy of Molecules and Crystals" (August 25-30, 2019, Odesa, Ukraine). 


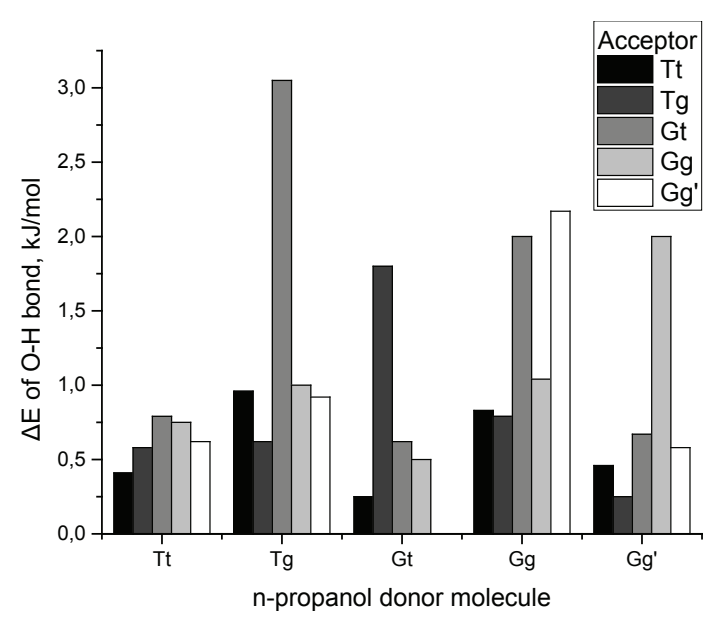

Fig. 1. Energy differences $\Delta E$ between the energies of a $\mathrm{Gg}^{\prime}$ Gt dimer (global minimum) and other dimers (without a solvent)

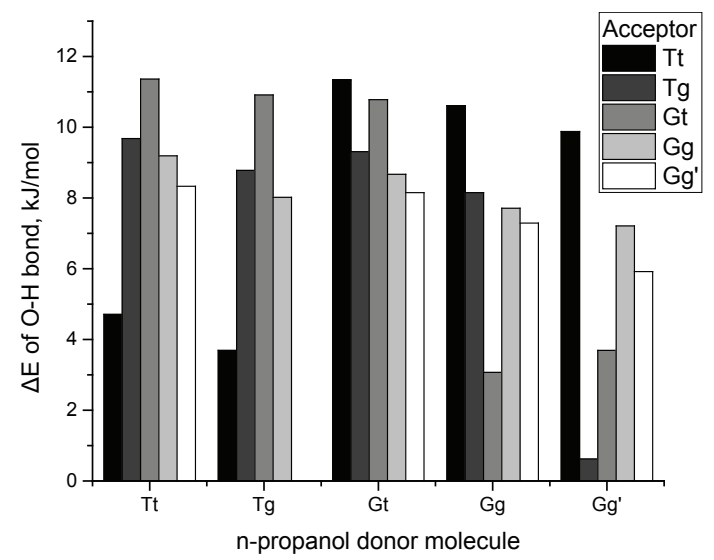

Fig. 2. Energy differences $\Delta E$ between a $\mathrm{Gg}^{\prime}-\mathrm{Tg}$ dimer (global minimum) and other dimers (with n-propanol as a solvent)

and the determination of a geometry, the Avogadro [27] and GaussView [28] softwares were used. Calculations were executed in several steps. The optimal geometry of monomeric conformers was calculated at the DFT B3LYP/cc-pVTZ level of theory. Vibrational spectra were additionally calculated for each of 5 n-propanol conformers (as was mentioned above, this alcohol has 9 conformers, 4 of which are enantiomers and have the same energy and optical parameters). Each conformer was designated by a symbolic title using a generally accepted scheme of dihedral angles $\mathrm{CCCO}+\mathrm{CCOH}$ via big + small letters for trans- $(T, t)$, gauche- $(G, g)$ and gauche'- $\left(G^{\prime}, g^{\prime}\right)$ conformers $[19,29]$. All the calculations were held for $\mathrm{n}-$ propanol as a solvent using standard Gaussian methods $\left(\varepsilon=20.524, \varepsilon_{\text {inf }}=1.918225\right)$. Then the energetically optimal geometries and harmonic IR absorption spectra for 25 possible dimers of n-propanol were calculated with the same level of theory. Each conformer was used 5 times as an acceptor and 5 times as a donor of proton (non-bonded and bonded molecules, respectively). The solvent interaction was considered as well. For all obtained geometries, a basis set superposition error (BSSE) and a complexation energy were calculated using the counterpoised method with "counterpoise $=2$ " keyword.

\section{Stability and Probability of Clusters}

Calculated values of the hydrogen bond energy in propanol dimers indicate the probability of cluster formation - the more the absolute value of the interaction energy, the higher the probability of the cluster existence. Figure 1 represents the calculated differences of energies of different n-propanol dimers and the energy of the most stable dimer $\mathrm{Gg}^{\prime}-\mathrm{Gt}$. The calculations were made without accounting the solvent interaction. As seen from Fig. 1, the most stable donor for each acceptor is a Tt conformer. Other donors have more stability fluctuations with different acceptors.

Including the solvent interactions in consideration leads to another global minimum for n-propanol dimers - $\mathrm{Gg}^{\prime}-\mathrm{Tg}$ configuration. Moreover, such an approach results in much bigger difference between dimer energies (Fig. 2). The explanation of such behavior can be found in the principle of molecular interactions. Calculated hydrogen bonds do not include the dielectric constant of alcohol (about 20.5, as mentioned before) that leads to a decrease of electric interactions in the substance. While the electric interaction is a general important part of the hydrogen bond formation, its decrease affects the stability of n-propanol clusters. In the further consideration, we will use the results of calculations with solvent interactions taken into account.

The distribution of dimers in n-propanol can be found as the Boltzmann one. Table 1 presents the results of this method applied for temperatures 298.15 K (liquid alcohol, room temperature), $200 \mathrm{~K}$ (liquid), $148.76 \mathrm{~K}$ (melting point [30]), and $100 \mathrm{~K}$ (solid).

As seen from Table 1, the most probable dimers are $\mathrm{Gg}^{\prime}-\mathrm{Tg}$ conformations. Moreover, the portion of $\mathrm{Gg}^{\prime}-$ 
Tg clusters raises, as the temperature decreases. At the same time, the contribution of other clusters decreases. The second among the most abundant dimers is a $\mathrm{Tg}-\mathrm{Gg}^{\prime}$ conformer. The dependence of its portion on the temperature is shown in Fig. 3. It is seen that the maximum percentage is $33.02 \%$ at $141-143 \mathrm{~K}$.

Thus, at room temperature $(298.15 \mathrm{~K})$, the contribution of five most stable configurations ( $\mathrm{Gg}^{\prime}-\mathrm{TG}$, Tg$\mathrm{Gg}^{\prime}$, Gt-Gg, Tt-Tg and Gt-Gg') is $77.12 \%$. At $200 \mathrm{~K}$, $147.05 \mathrm{~K}$, and $100 \mathrm{~K}$, the part of these structures rises to $91.88 \%, 97.39 \%$, and $99.67 \%$, respectively. At the melting point of n-propanol, the portion of $\mathrm{Gg}^{\prime}-\mathrm{Tg}$ and $\mathrm{Tg}-\mathrm{Gg}^{\prime}$ conformations is $87.34 \%$.

\section{Geometry of n-Propanol Dimers}

Detailed investigation of the dimerization process in n-propanol requires considering not only the cluster energy, but also their geometrical parameters. The important part of a dimer geometry is the difference between its structure and the structure of free molecules. Absolute values of dihedral deformations in the calculated dimers are presented in Table 2.

As seen from Table 2, the $\mathrm{Gg}^{\prime}$ conformer undergoes the biggest deformations as a donor molecule with each acceptor. Moreover, the gauche- $\mathrm{CCOH}$ dihedral is less stable than the trans-dihedral in a donor molecule.

Another important geometrical characteristic of a cluster is the radius of gyration (or gyradius, which will be used further). The calculated values of gyradii per axis for each dimer are presented in Table 3. Table 4 contains the ratio of gyradii for each cluster type. As seen, the most stable clusters, $\mathrm{Gg}^{\prime}-$ $\mathrm{TG}$ and $\mathrm{Tg}-\mathrm{Gg}^{\prime}$, have similar ratios. However, a less stable Gt-Gt has the same ratio as $\mathrm{Gg}^{\prime}-\mathrm{TG}$, but smaller absolute values (see Table 3 ).

For five most stable dimers, the big gyradii are $0.25-0.29 \mathrm{~nm}$, and small ones $-0.11-0.13 \mathrm{~nm}$. The volumes of such ellipsoids of gyration are (37, 30, $33,35$ and 30$) \times 10^{-3} \mathrm{~nm}^{3}$ for $\mathrm{Gg}^{\prime}-\mathrm{Tg}$, Tg-Gg', GtGg, Tt-Tg, and Gt-Gg' conformers, respectively (Table 5). Dimer Tt-Gt with the gyration ellipsoid volume similar to $\mathrm{Gg}^{\prime}-\mathrm{Tg}$ has a less elongate geometry (see Table 4) that can be resulted in a less stability of such structure.

\section{IR Absorption Spectra}

As mentioned in different works [2-6, 11-14], the clusterization of molecules in condensed alcohols leads to

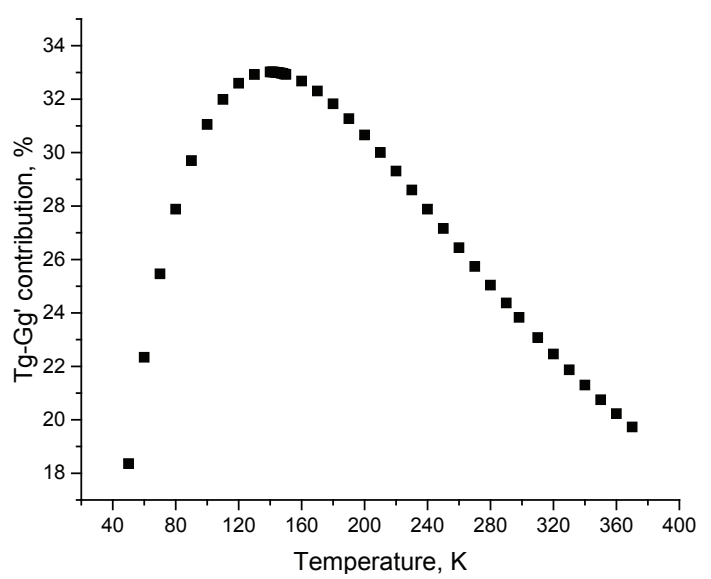

Fig. 3. Contribution of a $\mathrm{Tg}-\mathrm{Gg}^{\prime}$ conformer to the distribution of dimers in n-propanol at different temperatures

Table 1. Distribution of $\mathbf{n}$-propanol dimers at $298.15 \mathrm{~K}\left(\mathrm{~T}_{1}\right), 200 \mathrm{~K}\left(\mathrm{~T}_{2}\right), 148.76 \mathrm{~K}\left(\mathrm{~T}_{3}\right)$, and $100 \mathrm{~K}\left(\mathrm{~T}_{4}\right)$, solvent interaction included

\begin{tabular}{|c|c|c|c|c|c|c|c|}
\hline \multirow{2}{*}{\multicolumn{3}{|c|}{ Dimers portion, \% }} & \multicolumn{5}{|c|}{ Acceptor } \\
\hline & & & $\mathrm{Tt}$ & $\mathrm{Tg}$ & Gt & $\mathrm{Gg}$ & $\mathrm{Gg}^{\prime}$ \\
\hline \multirow[t]{20}{*}{ Donor } & $\mathrm{Tt}$ & $\mathrm{T}_{1}$ & 4.58 & 0.62 & 0.31 & 0.75 & 1.06 \\
\hline & & $\mathrm{T}_{2}$ & 2.62 & 0.13 & 0.05 & 0.18 & 0.30 \\
\hline & & $\mathrm{T}_{3}$ & 1.21 & 0.02 & 0.01 & 0.03 & 0.06 \\
\hline & & $\mathrm{T}_{4}$ & 0.23 & - & - & - & - \\
\hline & $\mathrm{Tg}$ & $\mathrm{T}_{1}$ & 6.91 & 0.89 & 0.38 & 1.20 & 30.60 \\
\hline & & $\mathrm{T}_{2}$ & 4.84 & 0.23 & 0.06 & 0.36 & 44.51 \\
\hline & & $\mathrm{T}_{3}$ & 2.75 & 0.05 & 0.01 & 0.08 & 54.39 \\
\hline & & $\mathrm{T}_{4}$ & 0.77 & - & - & - & 65.45 \\
\hline & $\mathrm{Gt}$ & $\mathrm{T}_{1}$ & 0.32 & 0.72 & 0.40 & 0.93 & 1.14 \\
\hline & & $\mathrm{T}_{2}$ & 0.05 & 0.16 & 0.07 & 0.24 & 0.33 \\
\hline & & $\mathrm{T}_{3}$ & 0.01 & 0.03 & 0.01 & 0.05 & 0.07 \\
\hline & & $\mathrm{T}_{4}$ & - & - & - & - & - \\
\hline & $\mathrm{Gg}$ & $\mathrm{T}_{1}$ & 0.42 & 1.14 & 8.87 & 1.36 & 1.62 \\
\hline & & $\mathrm{T}_{2}$ & 0.08 & 0.33 & 7.03 & 0.43 & 0.56 \\
\hline & & $\mathrm{T}_{3}$ & 0.01 & 0.07 & 4.55 & 0.11 & 0.15 \\
\hline & & $\mathrm{T}_{4}$ & - & - & 1.63 & 0.01 & 0.01 \\
\hline & $\mathrm{Gg}^{\prime}$ & $\mathrm{T}_{1}$ & 0.57 & 23.83 & 6.91 & 1.67 & 2.81 \\
\hline & & $\mathrm{T}_{2}$ & 0.12 & 30.66 & 4.84 & 0.58 & 1.27 \\
\hline & & $\mathrm{T}_{3}$ & 0.02 & 32.95 & 2.75 & 0.16 & 0.45 \\
\hline & & $\mathrm{T}_{4}$ & - & 31.05 & 0.77 & 0.01 & 0.05 \\
\hline
\end{tabular}

red shifts of the spectral bands corresponding to the frequencies of stretching $\mathrm{O}-\mathrm{H}$ vibrations. The authors of those works tried to compare the vibrational spectra obtained by quantum chemistry calculations with 
experimental ones using only one structure of each size. Molecules with fully trans-skeleton and gauche(gauche'-) CCOH dihedral are often used because of the traditional construction of molecules and clusters in the Avogadro/GaussView or other visualization software. Such a neglect of the conformer influence leads to the only partly correct results of comparison of the spectra.

Table 2. Absolute deformations

of molecule dihedrals in dimers

of n-propanol, solvent interaction included

\begin{tabular}{|c|c|c|c|c|c|c|}
\hline \multirow{2}{*}{\multicolumn{2}{|c|}{$\begin{array}{c}\text { Deformation } \\
\text { of donor CCCO } \\
\text { dihedral, degrees }\end{array}$}} & \multicolumn{5}{|c|}{ Acceptor } \\
\hline & & $\mathrm{Tt}$ & $\mathrm{Tg}$ & $\mathrm{Gt}$ & $\mathrm{Gg}$ & $\mathrm{Gg}^{\prime}$ \\
\hline \multirow[t]{5}{*}{ Donor } & $\mathrm{Tt}$ & 0.093 & 0.435 & 0.084 & 0.225 & 0.738 \\
\hline & $\mathrm{Tg}$ & 0.144 & 0.344 & 0.573 & 0.113 & 0.299 \\
\hline & Gt & 0.611 & 0.24 & 0.183 & 0.001 & 0.452 \\
\hline & $\mathrm{Gg}$ & 0.649 & 0.473 & 1.177 & 0.982 & 1.012 \\
\hline & $\mathrm{Gg}^{\prime}$ & 0.506 & 0.196 & 0.131 & 0.682 & 0.262 \\
\hline \multirow{2}{*}{\multicolumn{2}{|c|}{$\begin{array}{c}\text { Deformation } \\
\text { of donor } \mathrm{CCOH} \\
\text { dihedral, degrees }\end{array}$}} & \multicolumn{5}{|c|}{ Acceptor } \\
\hline & & $\mathrm{Tt}$ & $\mathrm{Tg}$ & Gt & $\mathrm{Gg}$ & $\mathrm{Gg}^{\prime}$ \\
\hline \multirow[t]{5}{*}{ Donor } & $\mathrm{Tt}$ & 0.008 & 1.465 & 0.198 & 2.557 & 4.731 \\
\hline & $\mathrm{Tg}$ & 5.202 & 5.468 & 7.204 & 6.928 & 5.115 \\
\hline & $\mathrm{Gt}$ & 0.462 & 0.258 & 2.512 & 1.859 & 1.391 \\
\hline & $\mathrm{Gg}$ & 6.232 & 5.386 & 6.553 & 6.71 & 7.144 \\
\hline & $\mathrm{Gg}^{\prime}$ & 16.477 & 17.584 & 17.322 & 15.902 & 17.035 \\
\hline \multirow{2}{*}{\multicolumn{2}{|c|}{$\begin{array}{c}\text { Deformation } \\
\text { of acceptor CCCO } \\
\text { dihedral, degrees }\end{array}$}} & \multicolumn{5}{|c|}{ Acceptor } \\
\hline & & $\mathrm{Tt}$ & $\mathrm{Tg}$ & Gt & $\mathrm{Gg}$ & $\mathrm{Gg}^{\prime}$ \\
\hline \multirow[t]{5}{*}{ Donor } & $\mathrm{Tt}$ & 0.148 & 0.439 & 0.741 & 0.265 & 0.0763 \\
\hline & $\mathrm{Tg}$ & 0.344 & 0.983 & 1.04 & 0.458 & 0.561 \\
\hline & Gt & 0.184 & 0.077 & 0.104 & 0.731 & 0.0913 \\
\hline & $\mathrm{Gg}$ & 0.263 & 0.033 & 0.246 & 0.583 & 0.2783 \\
\hline & $\mathrm{Gg}^{\prime}$ & 0.168 & 0.12 & 0.386 & 0.492 & 0.1214 \\
\hline \multirow{2}{*}{\multicolumn{2}{|c|}{$\begin{array}{c}\text { Deformation } \\
\text { of acceptor } \mathrm{CCOH} \\
\text { dihedral, degrees }\end{array}$}} & \multicolumn{5}{|c|}{ Acceptor } \\
\hline & & $\mathrm{Tt}$ & $\mathrm{Tg}$ & Gt & $\mathrm{Gg}$ & $\mathrm{Gg}^{\prime}$ \\
\hline \multirow[t]{5}{*}{ Donor } & $\mathrm{Tt}$ & 1.578 & 2.51 & 2.513 & 2.616 & 7.824 \\
\hline & $\mathrm{Tg}$ & 0.648 & 2.699 & 5.909 & 1.537 & 1.541 \\
\hline & $\mathrm{Gt}$ & 1.527 & 2.699 & 1.066 & 2.827 & 0.881 \\
\hline & $\mathrm{Gg}$ & 0.334 & 0.336 & 4.383 & 1.895 & 3.95 \\
\hline & $\mathrm{Gg}^{\prime}$ & 2.511 & 0.072 & 2.855 & 1.959 & 2.542 \\
\hline
\end{tabular}

As mentioned above, for each of 25 optimized dimer structures, IR absorption spectra were calculated. The obtained frequencies of free and bonded stretching $\mathrm{O}-\mathrm{H}$ vibrations are presented in Table 6 .

Table 3. Radii of gyration

per axis of $\mathbf{n}$-propanol dimers

\begin{tabular}{|c|c|c|c|c|c|c|}
\hline \multirow{2}{*}{\multicolumn{2}{|c|}{ Gyradius, nm }} & \multicolumn{5}{|c|}{ Acceptor } \\
\hline & & $\mathrm{Tt}$ & $\mathrm{Tg}$ & $\mathrm{Gt}$ & $\mathrm{Gg}$ & $\mathrm{Gg}^{\prime}$ \\
\hline \multirow[t]{15}{*}{ Donor } & \multirow[t]{3}{*}{$\mathrm{Tt}$} & 0.11 & 0.09 & 0.11 & 0.10 & 0.09 \\
\hline & & 0.29 & 0.32 & 0.27 & 0.29 & 0.31 \\
\hline & & 0.30 & 0.32 & 0.28 & 0.31 & 0.31 \\
\hline & \multirow[t]{3}{*}{$\mathrm{Tg}$} & 0.11 & 0.10 & 0.10 & 0.12 & 0.11 \\
\hline & & 0.27 & 0.29 & 0.27 & 0.27 & 0.28 \\
\hline & & 0.28 & 0.29 & 0.27 & 0.28 & 0.29 \\
\hline & \multirow[t]{3}{*}{$\mathrm{Gt}$} & 0.12 & 0.08 & 0.11 & 0.10 & 0.11 \\
\hline & & 0.26 & 0.31 & 0.27 & 0.29 & 0.27 \\
\hline & & 0.28 & 0.32 & 0.28 & 0.29 & 0.28 \\
\hline & \multirow[t]{3}{*}{$\mathrm{Gg}$} & 0.10 & 0.09 & 0.13 & 0.11 & 0.10 \\
\hline & & 0.27 & 0.29 & 0.24 & 0.27 & 0.28 \\
\hline & & 0.28 & 0.30 & 0.25 & 0.28 & 0.29 \\
\hline & \multirow[t]{3}{*}{$\mathrm{Gg}^{\prime}$} & 0.11 & 0.10 & 0.12 & 0.10 & 0.11 \\
\hline & & 0.26 & 0.26 & 0.24 & 0.27 & 0.27 \\
\hline & & 0.27 & 0.28 & 0.25 & 0.28 & 0.28 \\
\hline
\end{tabular}

Table 4. Ratio of gyradii

per axis for different dimer structures

\begin{tabular}{|c|c|c|c|c|c|c|}
\hline \multirow{2}{*}{\multicolumn{2}{|c|}{$\begin{array}{c}\text { Dimer anisotropy/ } \\
\text { Gyradius ratio }\end{array}$}} & \multicolumn{5}{|c|}{ Acceptor } \\
\hline & & $\mathrm{Tt}$ & $\mathrm{Tg}$ & Gt & $\mathrm{Gg}$ & $\mathrm{Gg}^{\prime}$ \\
\hline \multirow[t]{15}{*}{ Donor } & $\mathrm{Tt}$ & 0.36 & 0.28 & 0.40 & 0.33 & 0.29 \\
\hline & & 0.96 & 0.99 & 0.96 & 0.97 & 0.99 \\
\hline & & 1.00 & 1.00 & 1.00 & 1.00 & 1.00 \\
\hline & $\mathrm{Tg}$ & 0.39 & 0.35 & 0.37 & 0.42 & 0.39 \\
\hline & & 0.98 & 0.98 & 0.97 & 0.94 & 0.96 \\
\hline & & 1.00 & 1.00 & 1.00 & 1.00 & 1.00 \\
\hline & Gt & 0.43 & 0.24 & 0.39 & 0.36 & 0.40 \\
\hline & & 0.93 & 0.99 & 0.96 & 0.99 & 0.97 \\
\hline & & 1.00 & 1.00 & 1.00 & 1.00 & 1.00 \\
\hline & $\mathrm{Gg}$ & 0.37 & 0.31 & 0.50 & 0.50 & 0.34 \\
\hline & & 0.97 & 0.99 & 0.94 & 0.97 & 0.98 \\
\hline & & 1.00 & 1.00 & 1.00 & 1.00 & 1.00 \\
\hline & $\mathrm{Gg}^{\prime}$ & 0.40 & 0.38 & 0.47 & 0.38 & 0.39 \\
\hline & & 0.95 & 0.96 & 0.97 & 0.97 & 0.95 \\
\hline & & 1.00 & 1.00 & 1.00 & 1.00 & 1.00 \\
\hline
\end{tabular}

ISSN 2071-0194. Ukr. J. Phys. 2020. Vol. 65, No. 4 
Each spectral band was built as a Lorentz contour with a half-width of $1 \mathrm{~cm}^{-1}$ and the area equal to 1. Figures 4 and 5 present the total spectra (in the spectral regions of bonded and free stretching $\mathrm{O}-\mathrm{H}$ vibrations) of all considered dimer structures taking the probabilities of the cluster existence at different temperatures into account. The calculated intensities for each band were ignored. So, the results shown are only percentage, not absolute values. The infinite temperature means the equal distribution of all dimer structures.

As is seen from Fig. 4, there are two separated bands of bonded $\mathrm{O}-\mathrm{H}$ vibrations at room temperature in the spectrum of n-butanol dimers with additional contribution from both sides for each band. At the temperature of the phase transition $(148.76 \mathrm{~K})$, these less intense additional bands disappear, indicating a

Table 5. Calculated volumes

of the ellipsoids of gyration for n-propanol dimers

\begin{tabular}{|c|c|c|c|c|c|c|}
\hline \multirow{2}{*}{\multicolumn{2}{|c|}{$\begin{array}{l}\text { Volume of gyration } \\
\text { ellipsoid, } 10^{-3} \mathrm{~nm}^{3}\end{array}$}} & \multicolumn{5}{|c|}{ Acceptor } \\
\hline & & $\mathrm{Tt}$ & $\mathrm{Tg}$ & Gt & $\mathrm{Gg}$ & $\mathrm{Gg}^{\prime}$ \\
\hline \multirow[t]{5}{*}{ Donor } & $\mathrm{Tt}$ & 40 & 39 & 35 & 38 & 36 \\
\hline & $\mathrm{Tg}$ & 35 & 35 & 31 & 38 & 37 \\
\hline & Gt & 37 & 33 & 35 & 35 & 35 \\
\hline & $\mathrm{Gg}$ & 32 & 33 & 33 & 35 & 34 \\
\hline & $\mathrm{Gg}^{\prime}$ & 32 & 30 & 30 & 32 & 35 \\
\hline
\end{tabular}

Table 6. Frequencies of bonded

and free stretching $\mathrm{O}-\mathrm{H}$ vibrations in propanol dimers in the harmonic approximation

\begin{tabular}{|c|c|c|c|c|c|c|}
\hline \multicolumn{2}{|c|}{ Frequency, $\mathrm{cm}^{-1}$} & \multicolumn{5}{|c|}{ Acceptor } \\
\cline { 2 - 7 } \multicolumn{2}{|c|}{} & $\mathrm{Tt}$ & $\mathrm{Tg}$ & $\mathrm{Gt}$ & $\mathrm{Gg}$ & $\mathrm{Gg}^{\prime}$ \\
\hline \multirow{2}{*}{ Donor } & $\mathrm{Tt}$ & 3577.45 & 3575.86 & 3573.57 & 3575.02 & 3584.56 \\
& & 3812.20 & 3803.98 & 3815.67 & 3800.94 & 3823.43 \\
& $\mathrm{Tg}$ & 3578.48 & 3578.29 & 3576.23 & 3572.44 & 3577.1 \\
& & 3817.32 & 3801.82 & 3817.3 & 3800.12 & 3813.9 \\
& $\mathrm{Gt}$ & 3579.81 & 3580.02 & 3577.16 & 3577.87 & 3581.02 \\
& & 3812.49 & 3803.82 & 3817.23 & 3802.5 & 3813.06 \\
& $\mathrm{Gg}$ & 3576.88 & 3571.34 & 3574.78 & 3574.08 & 3584.97 \\
& & 3813.37 & 3799.78 & 3813.2 & 3800.21 & 3821.7 \\
& $\mathrm{Gg}$ & 3589.07 & 3587.19 & 3585.93 & 3586.23 & 3588.83 \\
& & 3815.84 & 3801.22 & 3816.47 & 3804.07 & 3817.99 \\
\hline
\end{tabular}

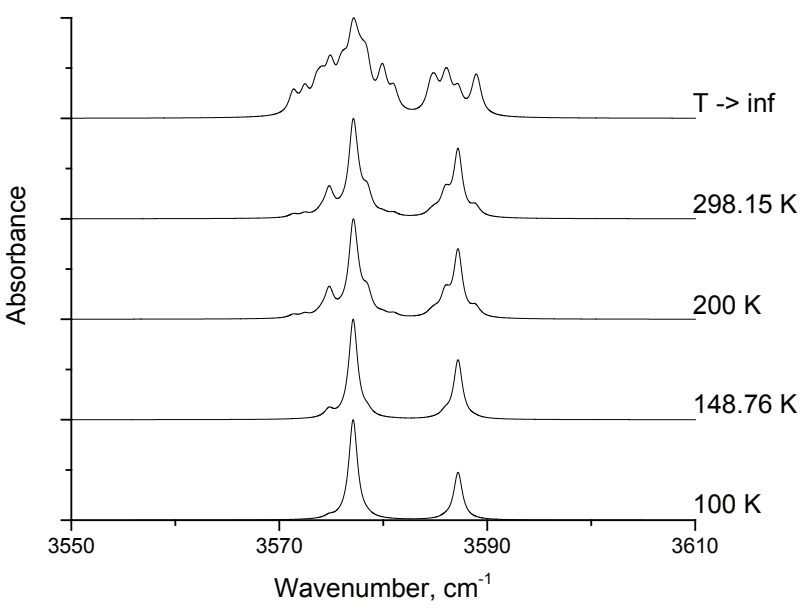

Fig. 4. IR absorption spectra of propanol dimers at different temperatures in the spectral region of the bonded stretching $\mathrm{O}-\mathrm{H}$ vibrations

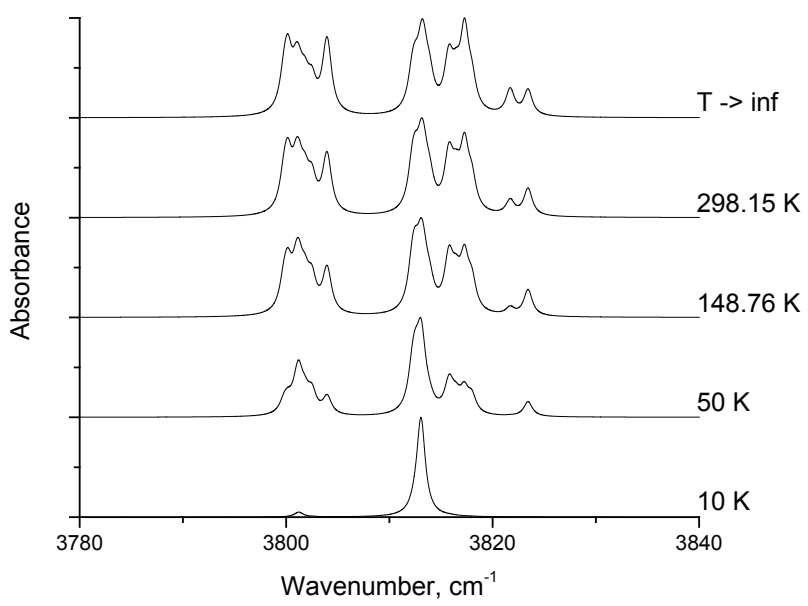

Fig. 5. IR absorption spectra of propanol dimers at different temperatures in the spectral region of free stretching $\mathrm{O}-\mathrm{H}$ vibrations

decrease in the contribution of corresponding clusters. As mentioned above, a halfwidth of each band was set to $1 \mathrm{~cm}^{-1}$, which corresponds to the width of a free molecule band. Bands of clusters are much wider. Otherwise, the simple including of the difference in frequencies between these main bands leads to the determination of a dimer bonded vibrational band of about $10.1 \mathrm{~cm}^{-1}$ in width in solid n-propanol and at least $12.4 \mathrm{~cm}^{-1}$ in liquid alcohol. A similar behavior can be seen in the spectra of free stretching $\mathrm{O}-\mathrm{H}$ vibrations (Fig. 5). The difference between vibrational bands can rise to $12.7 \mathrm{~cm}^{-1}$ in solid alcohol and up to $16.1 \mathrm{~cm}^{-1}$ in liquid n-propanol. 
Since the obtained frequencies were calculated in the harmonic approximation, they should be scaled (as one of the simplest ways to include the anharmonicity). Generally used scale factors are about 0.99. Applying this scale factor, the width of a possible vibrational frequency will be $10.0-12.3 \mathrm{~cm}^{-1}$ for the stretching $\mathrm{O}-\mathrm{H}$ vibrations of bonded hydroxyls and $12.6-15.9 \mathrm{~cm}^{-1}$ for the free stretching $\mathrm{O}-\mathrm{H}$ vibrations in n-propanol dimers. Moreover, in this work, only one possible configuration per each conformer pair was considered. If one includes more isomers for each dimer structure, the width of the corresponding spectral region can increase.

\section{Conclusions}

The ab initio study of the molecular conformation influence on the n-propanol dimerization has allowed us to draw several important conclusions. The clusterization in n-propanol strongly depends on the surrounding of alcohol molecules. While the clusterization in vacuum (and probably in a passive matrix isolation) hardly depends on the molecular isomerization, in condensed alcohol (considering the alcohol dielectric constant), more than a half of its structure is formed by only 2 of 25 possible combinations. $77.1 \%$ of n-propanol dimers at room temperature are formed by 5 most stable configurations $\left(\mathrm{Gg}^{\prime}-\mathrm{Tg}, \mathrm{Tg}-\mathrm{Gg}^{\prime}\right.$, Gt-Gg, Tt-Tg, and Gt-Gg'). At $200 \mathrm{~K}, 91.9 \%$ of dimers correspond to these configurations. At the melting point $(148.76 \mathrm{~K}), 87.7 \%$ of the dimer structure correspond to $\mathrm{Gg}^{\prime}-\mathrm{TG}$ and $\mathrm{Tg}$ $\mathrm{Gg}^{\prime}$ configurations.

The spectral dispersion of n-propanol dimers in the spectral region of bonded and free stretching $\mathrm{O}-\mathrm{H}$ vibrations can reach 12.3 and $15.9 \mathrm{~cm}^{-1}$, respectively. Such a value should be considered when comparing the calculated spectra with experimental ones.

The average volume of n-propanol dimers can be determined as $34.6 \times 10^{-3} \mathrm{~nm}^{3}$ by its gyration volume. This value can be used for a further determination of the alcohol density and the part of dimers in it.

All quantum-chemistry calculations presented in this work were performed on the Joint ISMA/STC ISC computational cluster of SSI "Institute for Single Crystals" and Institute of Scintillation Materials of the NAS of Ukraine.
1. A. Vrhovšek, O. Gereben, A. Jamnik, L. Pusztai. Hydrogen bonding and molecular aggregates in liquid methanol, ethanol, and 1-propanol. J. Phys. Chem. B 115 (46), 13473 (2011).

2. Y. Chernolevska, Y. Vaskivskyi, I. Doroshenko. Cluster Structure of Monohydroxyl Alcohols in Condensed State (LAMBERT Acad. Publ., 2016) [ISBN: 978-3-659-869952] (in Russian).

3. V. Pogorelov, Y. Chernolevska, Y. Vaskivskyi, L.G.M. Pettersson, I. Doroshenko, V. Sablinskas, V. Balevicius, J. Ceponkus, K. Kovaleva, A. Malevich, et al. Structural transformations in bulk and matrix-isolated methanol from measured and computed infrared spectroscopy. J. Mol. Liq. 216, 53 (2016).

4. I. Doroshenko, G. Pitsevich, V. Sablinskas. Cluster Structure of Liquid Alcohols: Vibrational Spectroscopy Study (LAMBERT Acad. Publ., 2012) [ISBN: 978-3-8484-22517] (in Russian).

5. Y.A. Chernolevska, I.Y. Doroshenko, V.E. Pogorelov, Y.V. Vaskivskyi, V. Sablinskas, V. Balevicius, A. Isaev. Theoretical and experimental researches of methanol clusters in low-temperature matrices. Ukr. J. Phys. 60 (11), 1089 (2015).

6. I. Doroshenko, V. Balevicius, G. Pitsevich, K. Aidas, V. Sablinskas, V.Pogorelov. FTIR/PCA study of propanol in argon matrix: The initial stage of clustering and conformational transitions. Low Temp. Phys. 40 (12), 1077 (2014).

7. M.I. Sulaiman, S. Yang, A.M. Ellis. Infrared spectroscopy of methanol and methanol/water clusters in helium nanodroplets: The $\mathrm{OH}$ stretching region. J. Phys. Chem. A 121 (4), 771 (2017).

8. M. Goulart, P. Bartl, A. Mauracher, F. Zappa, A.M. Ellis, P. Scheier. Electron-driven ionization of large methanol clusters in helium nanodroplets. Phys. Chem. Chem. Phys. 15 (10), 3577 (2013).

9. K. Bloch, C.P. Lawrence. Hydrogen bond lifetimes and clustering of methanol in carbon tetrachloride solutions. J. Phys. Chem. B 114 (1), 293 (2010).

10. T. Kobayashi, R. Shishido, K. Mizuse, A. Fujii, J.-L. Kuo. Structures of hydrogen bond networks formed by a few tens of methanol molecules in the gas phase: size-selective infrared spectroscopy of neutral and protonated methanol clusters. Phys. Chem. Chem. Phys. 15 (24), 9523 (2013).

11. I.Y. Doroshenko. Matrix isolation study of the formation of methanol cluster structures in the spectral region of $\mathrm{C}^{-}$ $\mathrm{O}$ and $\mathrm{O}-\mathrm{H}$ stretch vibrations. Low Temp. Phys. 37 (7), 604 (2011).

12. Y. Chernolevska, V. Pogorelov, Y. Vaskivskyi, I. Doroshenko. Temperature-induced evolution of a cluster structure in N-nonan-1-Ol: Experimental study and quantum-chemistry calculations. Ukr. J. Phys. 61 (6), 478 (2016).

13. G.A. Pitsevich, I.Y. Doroshenko, V.Y. Pogorelov, V. Sablinskas, V. Balevicius. Structure and vibrational spectra of gauche- and trans-conformers of ethanol: Nonempirical an-

ISSN 2071-0194. Ukr. J. Phys. 2020. Vol. 65, No. 4 
harmonic calculations and FTIR spectra in argon matrices. Low Temp. Phys. 39 (4), 389 (2013).

14. P. Golub, I. Doroshenko, V. Pogorelov. Quantum-chemical modeling of energy parameters and vibrational spectra of chain and cyclic clusters of monohydric alcohols. Phys. Lett. A 378, 1937 (2014).

15. D. Loru, I. Peña, M.E. Sanz. Ethanol dimer: Observation of three new conformers by broadband rotational spectroscopy. J. Mol. Spectrosc. 335, 93 (2017).

16. Y. Yu, Y. Wang, N. Hu, K. Lin, X. Zhou, S. Liu. $\mathrm{C}_{\beta}-$ $\mathrm{H}$ stretching vibrations as a new probe for conformation of n-propanol in gaseous and liquid states. Phys. Chem. Chem. Phys. 18 (15), 10563 (2016).

17. T.N. Wassermann, M.A. Suhm, P. Roubin, S. Coussan. Isomerization around $\mathrm{C}-\mathrm{C}$ and $\mathrm{C}-\mathrm{O}$ bonds in 1-propanol: Collisional relaxation in supersonic jets and selective IR photo-isomerization in cryogenic matrices. J. Mol. Struct. 1025, 20 (2012).

18. G.A. Pitsevich, I.Y. Doroshenko, V.E. Pogorelov, V. Shablinskas, V. Balevichus, E.N. Kozlovskaya. Nonempiric anharmonic computations of ir spectra of ethanol conformers in b3lyp/cc-pvqz approximation (stretch $\mathrm{C}-\mathrm{H}$ vibrations). Am. J. Chem. 2 (4), 218 (2012).

19. D. Katsikadakos, Y. Hardalupas, A.M.K.P. Taylor, P.A. Hunt. Hydrogen abstraction from n-butanol by the methyl radical: High level ab initio study of abstraction pathways and the importance of low energy rotational conformers. Phys. Chem. Chem. Phys. 14, 9615 (2012).

20. J. Moc, J.M. Simmie, H.J. Curran. The elimination of water from a conformationally complex alcohol: A computational study of the gas phase dehydration of n-butanol. J. Mol. Struct. 928, 149 (2009).

21. T.N. Wassermann, P. Zielke, J.J. Lee, C. Cézard, M.A. Suhm. Structural preferences, argon nanocoating, and dimerization of $\mathrm{n}$-alkanols as revealed by oh stretching spectroscopy in supersonic jet. J. Phys. Chem. A 111 (31), 7437 (2007).

22. V.G. Baonza, M. Taravillo, A. Cazorla, S. Casado, M. Cáceres. N-pentanol at high pressures: Rotational isomerism in the liquid phase and the liquid-solid phase transition. J. Chem. Phys. 124 (4), 44508 (2006).

23. M.A. Czarnecki, D. Wojtków, K. Haufa. Rotational isomerism of butanols: infrared, near-infrared and DFT study. Chem. Phys. Lett. 431, 294 (2006).
24. K. Kahn, T.C. Bruice. Focal-point conformational analysis of ethanol, propanol, and isopropanol. Chem. Phys. Chem. 6, 487 (2005).

25. K.B. Beć, Y. Futami, M.J. Wójcik, Y. Ozaki. A spectroscopic and theoretical study in the near-infrared region of low concentration aliphatic alcohols. Phys. Chem. Chem. Phys. 18 (19), 13666 (2016).

26. M.J. Frisch, G.W. Trucks, H.B. Schlegel, G.E. Scuseria, M.A. Robb, J.R. Cheeseman, G. Scalmani, V. Barone, B. Mennucci, G.A. Petersson, et al. Gaussian 09. Revision D.01, (Gaussian, 2013).

27. M.D. Hanwell, D.E. Curtis, D.C. Lonie, T. Vandermeersch, E. Zurek, G.R. Hutchison. Avogadro: An advanced semantic chemical editor, visualization, and analysis platform. J. Cheminform. 4 (1), 17 (2012).

28. R. Dennington, T.A. Keith, J.M. Millam. Gauss View, Version 5, (Semichem, 2009).

29. Ye. Vaskivskyi, Ye. Chernolevska, A. Vasylieva, V. Pogorelov, R. Platakyte, J. Stocka, I. Doroshenko. 1-Hexanol conformers in a nitrogen matrix: FTIR study and highlevel ab initio calculations. J. Mol. Liq. 278, 362 (2019).

30. CRC Handbook of Chemistry and Physics, edited by W.M. Haynes (CRC press, 2012).

Received 23.10.19

I. Дорошенко, Є. Васківсъкий,

Є. Чернолевсъка, Л. Мейлієв, Б. Куйлієв

\section{МОЛЕКУЛЯРНА ІЗОМЕРИЗАЦІЯ}

ДИМЕРІВ n-ПРОПАНОЛУ

$\mathrm{P}$ е $з$ ю м е

Досліджено молекулярні ізомери димерів n-пропанолу шляхом квантово-хімічного моделювання методом DFT. Було розраховано 25 комбінацій пар молекул з врахуванням діелектричної проникності пропанолу та без її врахування. Такий підхід дозволив авторам визначити найстійкіші конфігурації димерів пропанолу. Показано, що при кімнатній температурі загальну кількість димерів пропанолу складають переважно $(77,1 \%)$ лише 5 з 25 можливих конфігурацій, а при температурі плавлення - лише 2 комбінації $(87,3 \%)$. Розраховано розміри димерів та спектральну дисперсію в області валентних коливань вільних та зв'язаних О-Н груп. 